\title{
Penerapan Metode Steepest Ascent Hill Climb pada Permainan Puzzle
}

\author{
Hairul Anam*, Feby Sabilhul Hanafi**, Ahmad Fauzal Adifia***, \\ Ahmad Firdaus Ababil****, Saiful Bukhori***** \\ Fakultas Ilmu Komputer, Universitas Jember \\ * hairulanam21@gmail.com, ** febysabilhul@gmail.com, \\ *** adifia19@gmail.com,**** ahmad.firdaus.1054@gmail.com, \\ ***** saiful.ilkom@unej.ac.id
}

\begin{abstract}
Puzzle is one example of the application of artificial intelligence, in the process of completion there are many search algorithms that can be applied. The 8 puzzle solution will be faster obtained if the array principle is used with a variation of the Steepest-Ascent Hill Climbing (Hill Climbing algorithm by choosing the sharpest / steepest slope) with the correct heuristic parameters and distance heuristics and combined with LogList as the storage state ever passed to overcome the problems in the hill climbing algorithm itself and avoid the looping state that has been passed. Steepest Ascent Hill Climbing is an algorithm method that is widely used for optimization problems. The application of the SAHC (Steepest Ascent Hill Climbing) Algorithm to the puzzle is needed so that the game is completed with optimal time.
\end{abstract}

Keyword: Puzzle, Steepest Ascent, Hill Climb, Permainan, Kecerdasan Buatan

\section{Introduction}

Salah satu permainan yang umum dimainkan yaitu puzzle, banyak jenis permainan puzzle yang beredar di masyarakat baik yang masih tradisional bahkan sampai permainan yang berbasis android atau smartphone dengan beragam jenis dan permainan yang tidak hanya diperuntukkan bagi kalangan anak semata namun semua kalangan bisa menikmatinya. Menurut Patmonodewo (Misbach, Muzamil, 2010) kata puzzle berasal dari Bahasa Inggris yang berarti teka-teki atau bongkar pasang, media puzzle merupakan media sederhana yang dimainkan dengan bongkar pasang [3]. Dari pengertian tersebut dapat disimpulkan bahwa puzzle merupakan permainan yang edukatif, sangat berguna bagi perkembangan otak terutama bagi anak dalam proses pematangan berfikir. Puzzle sendiri dapat digunakan sebagai media pembelajaran. Sebagai media bermain dan belajar, media puzzle paling umum digunakan dalam menerapkan pembelajaran kepada anak-anak sekolah karena sederhana dan mencakup pembelajaran emosional dan mental yang diperlukan bagi anak seperti sikap tenang, sabar, dan ketekunan dalam menyelesaikan masalah, yang mana semua itu sangat diperlukan dan jika dilakukan dengan konsisten akan membentuk pola kepribadian yang baik bagi anak kedepannya.

Terdapat beberapa metode untuk membuat sebuah game puzzle tersebut diantaranya metode Steepest Ascent Hill Climbing, suatu metode pencarian berdasarkan nilai heuristik suatu fungsi yang memberikan nilai untuk perkiraan suatu solusi, metode ini sering digunakan untuk permasalahan optimasi. Pada metode Steepest Ascent Hill Climbing yang diimplementasikan pada permainan puzzle proses pengujian dilakukan dengan menggunakan fungsi heuristik. Pembangkitan keadaan berikutnya sangat tergantung pada feedback dari prosedur pengetesan "Tes yang berupa fungsi heuristik ini akan menunjukkan seberapa baiknya nilai terkaan yang diambil terhadap keadaan-keadaan lainya yang mungkin".

Langkah penyelesaian optimal untuk menyelesaikan puzzle, pada penelitian ini menggunakan metode Steepest Ascent Hill Climbing. Langkah-langkah dalam perhitungan SAHC (Steepest Ascent Hill Climbing) yaitu : (1) menghitung kotak yang menempati tempat yang benar, (2) hitung pergerakan yang memungkinkan. (3) mendapatkan nilai $h(n)$ menggunakan perhitungan manual dengan menggunakan penjumlahan kotak yang menempati tempat yang benar, (4) membandingkan nilai heuristic dari pergerakan yang mungkin, (5) menerapkan alur pencarian algoritma SAHC (Steepest Ascent Hill Climbing) dengan nilai heuristik h(n) yang telah diperoleh [2].

\section{Research Method}


Steepest Ascent Hill Climbing merupakan metode algoritma yang banyak digunakan untuk permasalahan optimasi. Salah satu penerapannya adalah untuk mencari rute yang terpendek dengan cara memaksimumkan atau meminimumkan nilai dari fungsi optimasi yang ada. Secara harfiah steepest berarti paling tinggi, sedangkan ascent berarti kenaikan. Dengan demikian steepest ascent berarti kenaikan paling tinggi. Jadi prinsip dasar dari metode ini adalah mencari kenaikan paling tinggi dari keadaan sekitar untuk mencapai nilai yang paling optimal [1].

Algoritma ini memeriksa titik (node), yaitu biaya (cost) yang dibutuhkan untuk mencapai sebuah node dan heuristik node / h(n) yaitu cost yang didapat dari node ke tujuan. Sehingga dapat dirumuskan sebagai berikut [2] :

$$
\mathrm{f}(\mathrm{n})=\mathrm{h}(\mathrm{n})
$$

- $\mathrm{f}(\mathrm{n})=$ perkiraan total cost terendah dari setiap path yang akan dilalui dari node $\mathrm{n}$ ke node tujuan.

- $\quad h(n)=$ perkiraan heuristik atau cost atau path dari node $n$ ke tujuan.

Untuk menentukan nilai $h(n)$ ditunjukan oleh persamaan 1, berikut :

1. $\mathrm{h}(\mathrm{n})=$

dimana :

$\mathrm{h}(\mathrm{n})=$ nilai heuristik untuk node / titik n

$\mathrm{Xn}=$ nilai koordinat $\mathrm{X}$ dari node / titik $\mathrm{n}$

$\mathrm{Yn}=$ nilai koordinat $\mathrm{Y}$ dari node / titik $\mathrm{n}$

$\mathrm{Xgoal}=$ nilai koordinat $\mathrm{X}$ dari node $/$ titik tujuan

Ygoal $=$ nilai koordinat $\mathrm{Y}$ dari node $/$ titik tujuan

Metode steepest ascent hill climbing ini merupakan pengembangan dari metode simple hill climbing. Bedanya adalah simple hill climbing menentukan next state dengan membandingkan current state (titik awal) dengan satu successor (titik persimpangan) dan successor pertama yang lebih baik akan dipilih menjadi next state. Sedangkan steepest ascent akan membandingkan current state dengan semua succesor yang ada didekatnya sehingga dalam steepest ascent hill climbing, next statenya merupakan successor yang paling baik atau paling mendekati tujuan [5].

Berikut adalah perbandingan algoritma steepest ascent hill climbing dengan hill climbing [2]:

Algoritma simple hill climbing:

1. Evaluasi state awal, jika state awal sama dengan tujuan, maka proses berhenti. Jika tidak sama dengan tujuan maka lanjutkan proses dengan membuat state awal sebagai state sekarang.

2. Kerjakan langkah berikut sampai solusi ditemukan atau sampai tidak ada lagi operator baru yang dapat digunakan dalam state sekarang :

a. Cari sebuah operator yang belum pernah digunakan dalam state sekarang dan gunakan operator tersebut untuk membentuk state baru.

b. Evaluasi state baru.

i. Jika state baru adalah tujuan, maka proses berhenti

ii. Jika state baru tersebut bukan tujuan tetapi state baru lebih baik dari pada state sekarang, maka buat state baru menjadi state sekarang.

iii. Jika state baru tidak lebih baik dari pada state sekarang, maka lanjutkan ke langkah

Algoritma steepest ascent hill climbing

1. Evaluasi keadaan awal (Initial State). Jika keadaan awal sama dengan tujuan (Goal state) maka kembali pada initial state dan berhenti berproses. Jika tidak maka initial state tersebut jadikan sebagai current state.

2. Mulai dengan current state = initial state.

3. Dapatkan semua pewaris (successor) yang dapat dijadikan next state pada current statenya dan evaluasi successor tersebut dengan fungsi evaluasi dan beri nilai pada setiap successor tersebut. Jika salah satu dari successor tersebut mempunyai nilai yang lebih baik dari current state maka jadikan successor dengan nilai yang paling baik tersebut sebagai new current state. Lakukan operasi ini terus menerus hingga tercapai current state $=$ goal state atau tidak ada perubahan pada current statenya.

Metode Steepest Ascent Hill Climbing, menggunakan algoritma sebagai berikut ini [2]: 
1. Mulai dari keadaan awal, lakukan pengujian, jika merupakan tujuan maka berhenti, dan jika tidak lanjutkan dengan keadaan sekarang sebagai keadaan awal.

2. Kerjakan hingga tujuan tercapai atau hingga iterasi tidak memberikan perubahan pada keadaan sekarang.

a. Misalkan SUCC adalah suatu state yang menjadi suksesor dari current state.

b. Untuk setiap operator bisa dilakukan terhadap current state, kerjakan:

i. Aplikasi operator tersebut dan bangkitkan new state.

ii. Evaluasi new state. Jika merupakan goal state, kembalikan state ini sebagai solusi dan keluar dari program. Jika bukan goal state, bandingkan new state dengan SUCC. Jika new state lebih baik dari SUCC, maka ganti SUCC dengan new state. Jika tidak lebih baik SUCC tidak perlu diganti.

c. Jika SUCC lebih baik dari current state, maka ganti current state dengan SUCC.

Pada Steepest Ascent Hill Climbing, ada tiga masalah yang mungkin terjadi, yaitu [4]:

a. Local Optimum : keadaan semua tetangga lebih buruk atau sama dengan keadaan dirinya.

b. Plateu : keadaan semua tetangga sama dengan keadaan dirinya.

c. Ridge : local optimum yang lebih disebabkan karena ketidak mampuan untuk menggunakan dua operator sekaligus.

\section{Result and Analysis}

Skema pengujian kasus yang dilakukan yaitu pada puzzle yang terdiri dari 8 angka yang harus diurutkan sehingga mencapai posisi yang diinginkan. Tujuan pengujian ini adalah menyelesaikan permainan puzzle dengan menggunakan metode steepest ascent hill climbing, yaitu memperhitungkan nilai heuristik yang dimiliki oleh setiap slide puzzle. Dimana pada puzzle diberikan initial state seperti gambar 2.

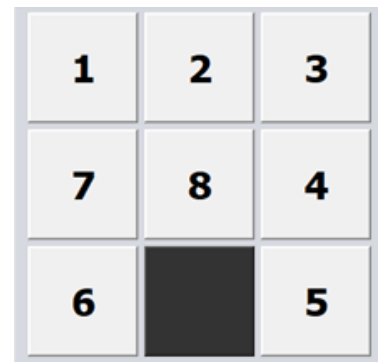

Gambar 2. Posisi awal puzzle (Initial state dengan heuristic 5)

Disini diketahui bahwa banyaknya angka yang menempati benar adalah 5 sedangkan 3 angka sisanya masih berada di posisi yang salah, maka banyaknya pilihan langkah yang bisa diambil dari posisi tersebut sebanyak 3 langkah, yaitu atas, kanan dan kiri.

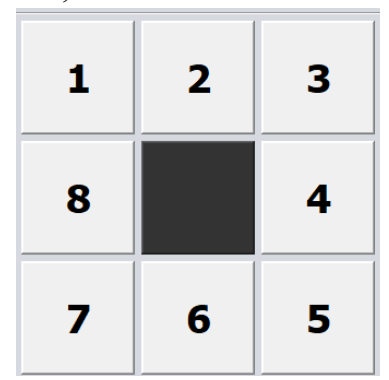

Gambar 3. Posisi akhir Puzzle (Goal state dengan heuristic 8)

Sedangkan posisi akhir (goal) dari permainan ini yaitu mengurutkan semua angka sesuai Gambar 3 dimana posisi angka dari 1 sampai 8 melingkari kotak perpindahan (kotak hitam).

Penyelesaian:

Berikut adalah langkah dari penyelesaian puzzle tersebut dengan steepest ascent hill climbing: 


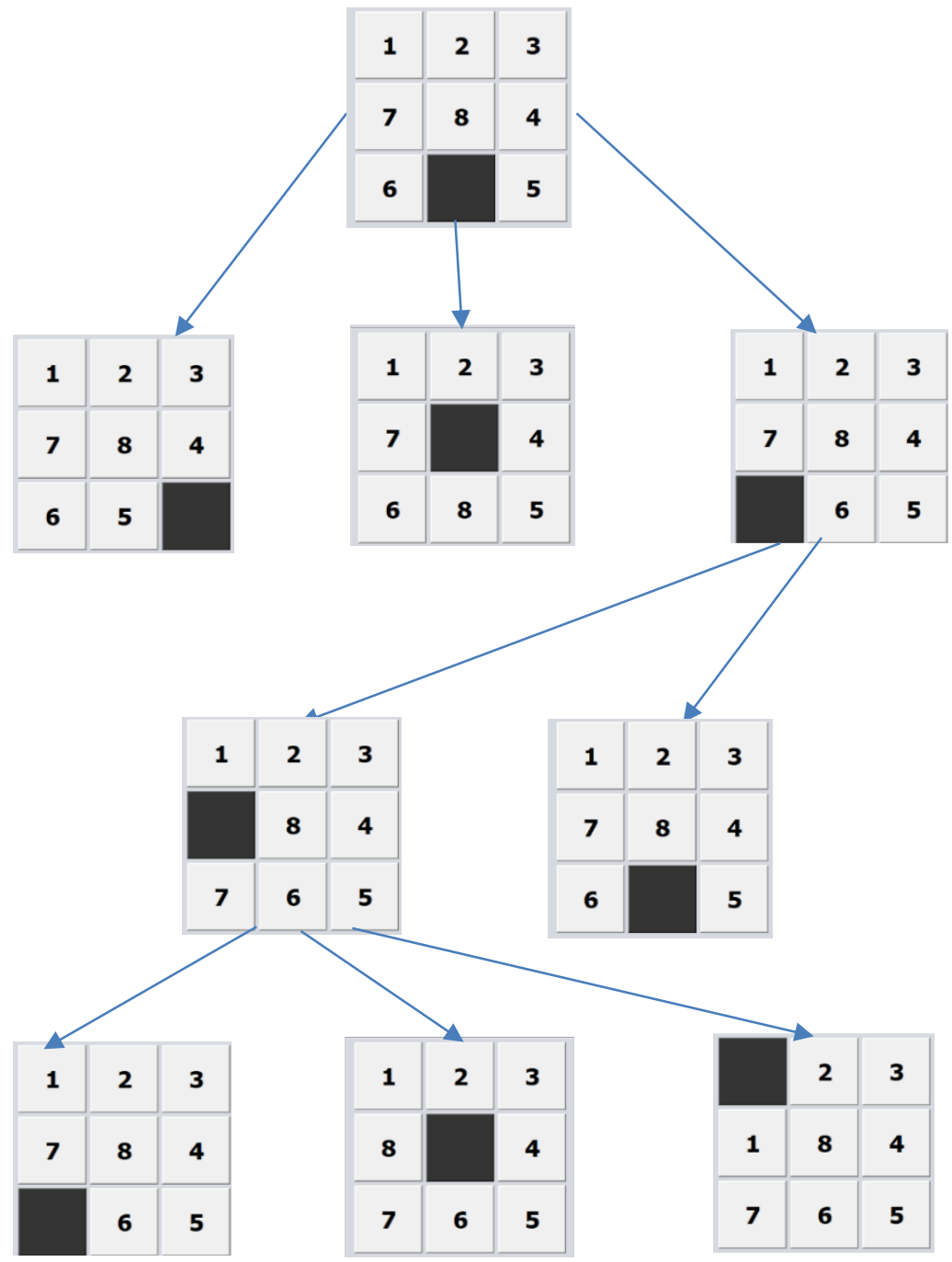

4. Alur penyelesaian puzzle menggunakan Steept Accent

Gambar

Dari Gambar 4, setiap slide puzzle kita ibaratkan sebagai node atau titik yang akan dilalui untuk mencapai goal state. Dimana pada setiap node memiliki nilai heuristik yang diperoleh dari jumlah angka yang menempati posisi benar.

Iterasi 1 :

Pada iterasi awal, terdapat 3 kemungkinan yang dapat dilakukan yaitu kemungkinan pertama menggeser angka 5 ke kiri dengan diperoleh hasil bahwa angka yang menempati posisi benar yaitu 1, 2, 3, 4 dan angka menempati posisi salah yaitu 5, 6, 7, dan 8 . Nilai heuristik diperoleh berdasarkan jumlah angka yang menempati posisi benar kemudian kita beri nilai 1 sedangkan angka yang menempati posisi salah kita beri nilai 0 sehingga :

$$
\text { Angka } \quad=1-2-3-4-5-6-7-8
$$

Nilai per angka $=1+1+1+1+0+0+0+0$

Nilai heuristik $=4$

Kemungkinan kedua dari iterasi pertama yaitu menggeser angka 8 kebawah. Dengan pemberian nilai sesuai kemungkinan pertama (yaitu 1 untuk angka pada posisi benar dan 0 jika salah), maka diperoleh hasil :

$$
\text { Angka } \quad=1-2-3-4-5-6-7-8
$$

Nilai per angka $=1+1+1+1+1+0+0+0$

Nilai heuristik $=5$

Kemungkinan ketiga dari iterasi pertama diperoleh hasil :

$$
\text { Angka }=1-2-3-4-5-6-7-8
$$

Nilai per angka $=1+1+1+1+1+1+0+0$

Nilai heuristik $=6$ 
Dari iterasi 1 tersebut hasil yang diambil adalah kemungkinan ketiga, karena pada kemungkinan tersebut mempunyai nilai heuristik yang paling besar diantara ketiga kamungkinan yang dapat dilakukan.

Untuk iterasi 2 dan seterusnya, langkah pengerjaannya menggunakan perhitungan yang sama dengan iterasi 1. Dalam kasus ini goal sudah tercapai dengan 3 iterasi. Berikut adalah hasil dari setiap iterasi:

Tabel 1. Hasil Iterasi Pemecahan Puzzle 8 angka

\begin{tabular}{|c|c|c|}
\hline Iterasi & $\begin{array}{c}\text { Nilai per angka } \\
(1-2-3-4-5-6-7-8)\end{array}$ & Heuristik \\
\hline & $1+1+1+1+1+0+0+0$ & 5 \\
\hline 1 & $1+1+1+1+1+1+0+0$ & 6 \\
\hline 2 & $1+1+1+1+1+1+1+0$ & 7 \\
\hline 3 & $1+1+1+1+1+1+1+1$ & 8 \\
\hline
\end{tabular}

Dari tabel diatas, dapat dilihat bahwa nilai heuristik terus bertambah hingga mencapai nilai maksimum sesuai dengan jumlah angka pada puzzle yaitu 8. Itu artinya, pada kasus ini metode steepest ascent mencapai global optimum dan tidak terjebak pada local optimum.

\section{Conclusion}

Dari hasil pengujian yang telah dilakukan, dapat disimpulkan bahwa metode steepest ascent hill climbing bisa diterapkan dalam permainan puzzle dengan mempertimbangkan nilai heuristik dari langkah selanjutnya. Penyelesaian puzzle dengan steepest ascent bergantung pada inisialisasi state awal yang diberikan karena hal itu akan berpengaruh pada nilai heuristik yang dimiliki. Oleh karenanya adakalanya puzle mencapai posisi terbaik yang diinginkan bisa disebut global optimum. Namun terkadang akan mencapai local optimum yaitu ketika posisi puzle tidak mencapai goal state.

\section{Acknowledgements}

Terimakasih atas bantuan dan bimbingan prof Saiful bukhori sehingga artikel ini dapat tersusun. Artikel ini merupakan output mata kuliah di fakultas ilmu komputer.

\section{References}

[1] Kusumadewi, S. (2003). Artificial Intelelligence.Jogyakarta: Graha Ilmu

[2] Zemma, L. A., \& Qur, A. (2015). Penerapan Metode Steepest Ascent Hill Climbing Pada Model Pencarian Rute Terdekat Fasilitas Pelayanan Darurat Di Kota Bogor Berbasis Android.

[3] Puzzle (online) (http://www.academia.edu/9717051/, diakses pada tanggal 19 Oktober 2017).

[4] Zakiah, A., \& Masalah, R. (2012). Penyelesaian Masalah 8 Puzzle Dengan Algoritma Hill Climbing, (Sentika), 158-163.

[5] Uriawan, W., Faroqi, A., Fathonah, R., Informatika, J. T., Sains, F., \& Negeri, U. I. (2015). Game slider puzzle. Pembuatan Game Slider Puzzle Menggunakan Metode Steepest Ascent Hill Climbing Berbasis Android, IX(1), 204-221. 